\title{
Foodie's Behavior and Assessment of Popular-Commercial Foods
}

\author{
Lily Dianafitri Hasan ${ }^{1}$, Faisal Akbar Zaenal ${ }^{1}$, Intan Fauziah Amaliah ${ }^{1}$ \\ Corresponding email: lilydianafitry@poltekparmakassar.ac.id \\ ${ }^{1}$ Hospitality, Catering Management, Makassar Tourism Polytechnic, Indonesia
}

\begin{abstract}
This study aims to describe foodies assessing popular-commercial foods. In this study, the method used is a qualitative method. The informant determination technique used is purposive (deliberate). The data collection used is by observation, in-depth interviews with informants, and confirmed by various literature studies that are relevant to the research topic. The results showed that from the taste, feeling related to service, and the condition of the place to eat, nothing could stand alone as the most dominant in determining a foodie's assessment of food. One of these factors can invalidate a good rating on the other factor. On the other hand, in conducting an assessment, foodies base their general assessment of expectations on the image of the food, the food maker, the place to eat and also the price of the food.
\end{abstract}

Keywords: Rating, Food, Popular-Commercial

Received: October 9, 2021

Revised: November 15, 2021

Accepted: November 26, 2021

\section{Introduction}

Establish several theories regarding the segmentation of the culinary market which refers to the analysis of activities, motivations and outputs in the tourist sphere. It was further explained that the emergence of various culinary market segments could not be separated from the dominance of the influence of the foodie movement who tried to enjoy a variety of food offerings wrapped in individual characteristics that seemed humble. In other words, being a foodie is part of a trend that everyone can follow. This assumption refers to the global movement regarding food quality as well as the movement to support the development of local culinary production - the preference of local products with respect to ecology and organics. However, it does not appear that some groups and/or individuals respond to the foodie movement as part of an elite trend foodie is another term for gourmet who is pampered with various forms of stunning consumption services that collect cultural capital through the activity of consuming a variety of food offerings. as well as people who have a lifestyle, then open a room for discussion and share information about their experiences when enjoying a variety of food offerings that economically can only be done by the upper class and educated.

However, Kline et al. (2015) argue that this view cannot define a foodie; regardless of whether this behavior is related to the consumption pattern of the elite - enjoying five-star hotel services or visiting local markets because being a foodie is a personal identity and/or a form of selfactualization.

Through research by Ambrozas (2004) related to foodie activities such as cooking, shopping and studying food. So he concluded that the foodie is a person with some labeling related to his identity formed by the activity of consuming quality food and being familiar with various commercial food products, where information related to commercial food products is found from a number of media such as culinary magazines, TV programs and other promotional activities related to with food processing. 
Furthermore, Johnston \& Bauman (2015) divide foodies into 4 (four) contexts: (1) education regardless of formal education level, foodies are individuals who have an interest in learning about food; (2) identity - foodies place food as a part of themselves, this is also closely related to family traditions that have shaped their childhood and/or how foodies see and perceive the world; (3) exploration - the tendency of foodies is to always want to enjoy and/or just taste a variety of new types of food, various types of cuisine, and new recipes; (4) evaluation - for foodies, the word evaluation is a synonym for the word enjoyment, because they are always enthusiastic in discussing or just talking about food.

While Cairns et al. (2010) understand the foodie as a non-professional individual in the field of food processing, but has a strong desire to enjoy a variety of food offerings and learn the ins and outs of the culinary world in a relatively short duration of time. So then Cairns et al. (2010) define foodie as a hobby that requires cultural and economic capital, therefore foodies always get special privileges.

Implicitly the opinion of Cairns et al. (2010) confirmed by Getz and Robinson (2014) through the results of their study related to the travel experience of foodies, then they defined it as an individual who has a passion for food and has an intense level of involvement in various culinary activities.

A similar definition has been previously presented by Bourdain (2012) that foodie is a general term that describes a person's interest in various types of food, various types of cuisine, and restaurants; However, the term foodie has developed and has led to a bad reputation - it tends to be associated with arrogance and fashion - so a number of individuals reject the term and prefer to label themselves as 'culinary enthusiast'.

Referring to the opinion of the experts above regarding the definition of the term foodie, it can basically be understood that the term foodie is a label for individuals who place food no longer as a mere physiological need, but has been placed as something to be loved. As the results of further analysis, Getz \& Robinson (2014b) conclude that foodie is a label for individuals who integrate food, food preparation and processing processes and enjoy a variety of food offerings into their lifestyle, and become personal and social identities because they are always surrounded by a variety of activities. culinary, cooking, sharing food and culinary information. Likewise with Wilkinson (2016) who identifies a foodie with a 'food lover', namely (1) someone who integrates food quality, cooking and sharing culinary experiences as part of personal and social identity; (2) placing the food aspect holistically as part of a lifestyle, so that it becomes a driving factor for travel and/or movement to find new and/or authentic culinary experiences.

Further Kline et al. (2018) argues that foodie is a term and/or labeling that refers to the description of individuals who have a passion and interest in food, thus encouraging them to travel or attend events and/or participate in culinary-related activities such as culinary festivals, demo classes or cooking training.

The emergence of various definitions of foodie as described above, leads to understanding as a result of an incomplete study, therefore the foodie phenomenon is still in the phase of the subject of research that requires a more in-depth analysis; through a research entitled Foodie in the UK: A Sense of Self, Connection and Belonging Beyond the Passion?, he found that the term foodie is not limited to an implicit description of someone who is interested in food; because substantially foodie labeling refers to the extent to which a person's involvement and level of attention and/or interest in five categories and/or cultural themes, namely (1) learning and discovery - refers to enthusiastic behavior towards culinary knowledge and experimenting 
with various types of cuisine and food ingredients without following the proper recipe, this is done with the aim of enriching oneself with information and/or preferences for food; (2) pleasure and enjoyment - this category focuses on 'active enjoyment' in enjoying food, where enjoying a variety of foods is considered a hobby and is intrinsically perceived as selfsatisfaction and pride; (3) inspirational influence - refers to the involvement of online popular culture through blogging or other media that highlights commercial food consumption activities and the support of influence from other or external people, such as family and friends as a starting point for the emergence of an interest in food; (4) quality - this category focuses on caring and respecting food, respecting food quality, sourcing food and food supplies, and preferring local markets and independent suppliers; and (5) experienceng food as an individual and in connection with others - this category refers to a foodie's experience with food and the taste of food both in the home environment to upscale restaurants, either individually or with others in tasting a variety of new foods and/or enjoy a moment that is integrated with learning and enrichment, where the view of the dominance of taste identity always accompanies a foodie.

It is possible that in foodie culture there are different levels of taste, which leads to how early the development of the foodie typology was. This view also refers to Atkinson's (2013) review published in The Sunday Times with the topic 'The New Young Foodie Culture', which in general explains that foodie culture has also experienced growth to touch the lifestyles of young people.

student; Although foodie cannot be separated from the scope of higher tastes in choosing food when compared to non-foodie tastes, it is not significantly identified with expensive food like gourmets as some people think that identify with foodie (Johnston \& Bauman, 2015).

Watson et al. (2008) previously examined the differences between foodies and gourmets, which found that gourmets tended to come from the older and upper classes; while the foodies emerge from young couples from the ambitious class who have grown up as 'children of the consumption craze; they criticize the dishes they eat in restaurants and then try to make them at home; they collect dining experiences like tourists collect souvenirs; and they try and/or attempt to visit famous restaurants.

Regarding the origin of the term foodie, if we look into the past, information is found that the term is a word, a concept, a person's identity. Appeared in the early 1980s and was first used by New York author Gael Greene when reviewing the existence of a number of restaurants as a concise description of the joy of restaurant guests during and/or after enjoying beautifully and attractively served food. However, the term foodie was further popularized by Ann Barr and Paul Levy in 1985 through a book entitled The Official Foodie Handbook; which in the book outlines explains that a foodie is not a gourmet, therefore a foodie does not behave arrogantly, does not have to come from a professional circle or is limited to only men; foodie is not someone with pathological overeating behavior because for foodie the activity of consuming food tends to fulfill the demands of his body from the neck up - mind, mouth, soul - not from the neck down (Levy. Paul, 2007; Vadnal, 2020;).

Through the writings of Barr \& Levy (1985) it was found that in general, foodies idolize food and place food on a par with works of art; foodies do not come from or are not pegged to a particular community and/or circle, in other words they tend to refer to personal culture. Furthermore, Barr \& Levy (1985) stated that the foodie culture is a behavioral trend in the late twentieth century that emerged by the impulse of desire. 
Meanwhile, Ambrozas (2004) conceptualizes foodies more deeply as cultural and social experts who consider the order of cultural distinctions above the socio-economic structure. For example, consuming exotic and/or expensive local foods such as 'pomegranate molasses' is a representation of the interaction of cultural capital. And at the same time, the preference of foodies to consume local and organic food is a symbol of their opposition to the application of agricultural industrial technology in terms of genetic engineering, on the other hand foodies are more supportive of alternative farming practices and become part of their culinary capital indicators.

Furthermore, Ambrozas (2004) claims that in order to differentiate themselves from consumer behavior as a whole, foodies are more aware and understand aspects of social life. Foodies are very concerned with ecological sustainability and authenticity as part of their dining experience and most of their choices are based on a desire to limit industrialization in food product processing systems (Johnston \& Bauman, 2015).

Based on the sequence of views of the experts above, it can be interpreted that foodies place food as part of the pleasures of life and entertainment media; In addition, foodies take advantage of their knowledge and are always enthusiastic about studying culinary sciences to collect cultural capital and differentiate themselves from other food consumers, which in turn builds their own identity. As the opinion of Cairns et al. (2010) which emphasizes that food for foodies is a great personal investment; they are independently committed to exploring the 'education of palate', because they consider food and/or culinary knowledge as cultural capital so that in some ways it will position themselves differently from food consumers in general.

As stated by Watson et al. (2008) that foodie activities in collecting dining experiences are similar to tourist activities in collecting souvenirs or taking photos of monuments in a tourism destination and visiting various famous restaurants (Watson, 2013). Likewise, Robinson \& Getz (2014) through their study, places the foodie in the context of tourists seeking experiences through culinary tourism; it was found that most of the samples that labeled themselves as foodies had a high level of food-involvement - one third of the total sample subscribed to culinary magazines; one-fifth as a blog writer or engage in online discussion forums on food and beverage topics; $6 \%$ are members of a community and/or food club; $11 \%$ belong to a wine club. Regarding travel behavior, it was found that one third of the research sample had planned a tourist trip in the following year with the agenda of enjoying culinary and/or domestic food a variety of culinary delights found in their own country or in certain countries.

Furthermore, through a similar study, Getz \& Robinson (2014a) argue that the link between foodie and travel activities is a strong indicator in building the culinary tourism industry. Which in his study describes that foodies are very

enthusiastic and concerned with local authenticity, traditions and customs. In line with that, foodies during their travels always refer to authentic eating and/or culinary experiences with local culture, learn about the variety of local food offerings, and become a social space with the theme of eating and/or culinary experiences (Getz \& Robinson, 2014b).

The latest discourse regarding the foodie phenomenon is described by Vadnal (2020) which is contained in shondaland.com with the title Everyone's a Foodie Now. Which he described that if the foodie in the 1980s referred to the depiction of class differences and/or economic strata; the era of the 1990s was a trend of behavioral change which was shown by fanaticism towards various types of food, giving rise to a culinary explosion; then in the second half of the decade and the beginning of the 2000s, celebrity chef through the support of The Food Network became a new profession that was idolized by various circles; where this change is certainly 
inseparable from the role of the development of information technology. It was further explained that today nothing democratizes foodies more than the role of social media, where almost the entire subset of content is dedicated to foodporn as visual platforms grow and advance like Snapchat, Instagram, and now TikTok. Thus, it cannot be denied that foodie does not only exist but is now spreading everywhere, therefore social media platforms have brought the role and function of food further forward and become an increasingly competitive obsession in producing style and content that seems to transcend the role and function of food. as a basic need. This discourse also reinforces Mohsen's (2017) view that studies related to the foodie phenomenon still require further exploration from various points of view

\section{Methods}

This study uses a qualitative approach. Further explained by Bryman and Bell (2011), qualitative research is interpretivist and adopts a constructivist perspective; so the researcher considers the qualitative research approach very suitable to be applied to this research; because this research focuses on consumers and consumption practices that affect social interactions.

The type of qualitative research applied is an ethnographic approach that allows researchers to better understand the foodie phenomenon and its influence on social interaction. The research carried out uses ethnography as a research design, because; The research focuses on foodie culture, especially with regard to the reasons and ways of choosing, consuming, and evaluating popular-commercial foods, so that culture exists only among foodie groups and/or communities. The implication of the application of the ethnographic research design is the application of two distinctive methods in it, namely participant observation and ethnographic analysis.

This research was carried out in Makassar City, which today has become a city center for business turnover, trade as well as the most advanced advances in knowledge and technology in the central and eastern parts of Indonesia.

The selection of informants in this study aims to select individuals who are willing to share their experiences and consumption behavior in this case consuming food and beverages. Therefore, the first criterion in selecting informants for this research is that they must be foodies. The definition of foodie used as the informant selection frame refers to the definition of foodie by Getz \& Robinson (2014b) which is labelling for individuals who integrate food, food preparation and processing processes and enjoy a variety of food offerings into their lifestyle, and become personal and social identities. because it is always covered with a variety of culinary activities, cooking, sharing food and culinary information

\section{Results and Discussion}

\section{Foodies Behavior}

In the context of behavior, foodies have several characteristics among them. First, above the awareness that everyone has a different 'tongue', taste adjustment or customization of a food is one of the typical behaviors among them.

Sultan ( 22 years old) said that when he wanted to eat meatballs, he would first try the broth from the meatballs without mixing it with any additional seasoning. But only after that did he 'mix' the meatballs according to his taste or 'tongue'.

Furthermore, Diyan (34 years old) said that many in his foodie circle have differences in preparing food, for example meatballs. Some of the friends like to eat meatballs with gravy that is not mixed with anything. But he made the sambal on another plate to be eaten separately with the meatballs. He did this to keep the original taste of the meatball sauce. And there are 
also some friends who like to mix a lot of soy sauce or chili directly into the meatball sauce, and eat it together with the meatballs.

In addition, there is also a behavior that he also refers to as a symptom of 'eyes hungry'. This symptom is ordering many types of food on the table because they feel happy when they see there is a lot of food available on the table. This is also inseparable from his desire to be able to eat various types of food in one visit with his friends.

A foodie also often does eating activities together with his circle of friends. The circle of friends referred to here is 'eating friends', or what Pipi (26 years old) calls frequency friends, or fellow foodies. Here, a place to eat is not only used as a place to eat, but is not complete if it is not accompanied by discussions about the food being eaten, judgments that compare the place with other places both in terms of food or the comfort of the place.

In his discussion, He who has had the experience of eating at a dining place, will act as a reference center on what should and should not be ordered at that place. If the recommended foods are 'successful', in other words make their friends satisfied, the person who has acted as the center of the recommendation will feel satisfied and proud. This then continues into the recognition of his friends as people who are 'experts' in recommending food at the place. In other contexts, those who may have knowledge of a specific food, will also be recognized as the main person to be referred to regarding certain foods, such as Korean food, Chinese cuisine, and so on.

\section{How is it delicious?}

Sultan (22 years old) said that delicious according to him is the compatibility of pleasure from the tongue, mind and heart (feelings). The tongue speaks of taste. Regarding this, foodies agree that conformity to expectations about taste is very relative among all people. But there is one thing that applies generally among fellow foodies, namely the freshness of a food. Whatever the type and taste of the food, the freshness of the food comes first.

Pipi (23 years old) once complained to a restaurant that provided fried eggs that were not fresh, aka cold (not hot). Pipi's expectations at that time, when we dined on the spot, meant that we would get a fresher dish (warm, hot, freshly cooked) than take away or eating at home. Because of the high expectations, Pipi forced the restaurant waiter to exchange the eggs for new and 'fresh' ones. Even though the waiter had stated that he had complied with the procedure, or in other words, that was the standard of providing food at the place, Pipi still insisted on returning the eggs. As a result, even though Pipi's request has been granted, she has put the restaurant on the black list of places to eat.

In addition to the egg, we can see evidence that freshness is the main thing in the food ordering behavior of foodies who always try to eat at a place to eat directly rather than ordering via online ordering. Especially the menus of soupy foods. Rikar (34 years), Diyan (34 years) and Diana (40 years) said that, especially foods with soup, it is very 'haram' to eat them out of place. In addition, at the same time, when a foodie visits a restaurant directly, he evaluates the level of cleanliness of the food processing, whether it is cooked side by side with food ingredients that are forbidden in Religion, and at the same time knows the exact location of the place where the food is sold so that it can be used as capital. conversation or discussion with other foodie friends.

The second is the suitability of taste in the imagination of the foodie. For example, there are some foods that are considered unreasonable to them. Pao (31 years old) said that he was never 
interested, even just trying popular commercial foods such as chocolate stuffed meatballs, spicy chocolate fried chicken, because he could associate these menus into the flavors in his head.

The third is a certain timing or moment. For example after coming home from sports, at the same time the body will become tired and lack of energy. According to Galuh ( 23 years old) at a time like that, usually all food, as long as it is still worth eating, will taste good to eat. Or when conditions are cold due to continuous rain, then according to Pao (31 years), the best food is soupy and hot food.

Fourth is the service dimension. Many even, foods that are known to be delicious, but become unpleasant immediately because they cannot satisfy the feeling when they want to eat them. This feeling is often disturbed by the service aspect of a restaurant. Bella ( 25 years old) said that the forms of service that often disturb the feeling of eating are services that seem 'cheeky', fickle, and provide food for a long time

\section{Conclusion}

Knowledge of the process of a foodie's life experience and its relationship with food creates behavior that 'seats' food as an object of self-actualization and reproduction. Food has also become a medium for foodies to express themselves and their knowledge of food both for selfsatisfaction and as a 'gift' to the people around them. In the dimensions of knowledge and behavior towards food, there is a process of evaluating food that has become part of the discussion about food and the basis for a foodie to satisfy himself or the people around him. From the taste, feeling related to service, and the condition of the place to eat, nothing can stand alone as the most dominant in determining a foodie's assessment of food. One of these factors can invalidate a good rating on the other factor. On the other hand, in conducting an assessment, foodies base their general assessment of expectations on the image of the food, the food maker, the place to eat and also the price of the food.

\section{References}

Ambrozas, D. (2004). Serious feast: Vancouver foodies in globalized consumer society. ProQuest Dissertations and Theses, December, 258-258 p

Atkinson, Paul., dan Hammersley, Martyn. (2009). Etnografi dan Observasi Partisipan. Dalam Norman K. Denzin dan Yvonna S. Lincoln (Editor), Handbook of Qualitative Research, diterjemahkan oleh Dariyanto, Badrus Samsul Fata, Abi, dan John Rinaldi, Penerbit Pustaka Pelajar

Barr, A., \& Levy, P. (1985). The Official Foodie Handbook: Be Modern - Worship Food (Harper and Queens (ed.). Arbor House Publishing Company

Bourdain, R. (2012). Comfort Me with Offal. Andrews McMeel Publishing, LLC

Bryman, A. Bell, E. (2011). Business Research Methods. 3rd edition. Oxford University Press

Cairns, Kate., Johnston, Josée., \& Baumann, Shyon. (2010). Caring about Food; Doing Gender in the Foodie Kitchen.

Getz, D., \& Robinson, R. N. S. $\left(2014^{\mathrm{A}}\right)$. Foodies and Food Events. Scandinavian Journal of Hospitality and Tourism, 315330.https://doi.org/10.1080/15022250.2014.946227

Johnston, J., \& Bauman, S. (2015). Foodie: Democracy and Distinction in the Gourmet Foodscape (Second Edi). Taylor \& Francis 
Kline, Carol S., dan Greenwood, Jerusha. (2015). Exploring Foodie Segmentation. Journal of Tourism Insights; Applied Research in the Commercial Recreation, Event and Travel Industries, 6(1), Digital Commons. DOI: 10.9707/23280-0824.1049

Levy. Paul. (2007). What is a foodie? | Food | The Guardian. Theguardian.Com Society, 24(5), SAGE Publications.

Vadnal, J. (2020). Everyone's a Foodie Now. Shondaland.Com

Watson, Pamela Jeaneette, Morgan, M., \& Hemmington, N. (2008). Online communities and the sharing of extraordinary restaurant experiences. Journal of Foodservice, 19(6), 289-302. https://doi.org/10.1111/j.1748-0159.2008.00110.x

Wilkinson, P. F. (2016). Foodies and food tourism. Annals of Leisure Research, 19(1), 139141. https://doi.org/10.1080/11745398.2015.1072729 